

\section{DISCLAIMER}

This report was prepared as an account of work sponsored by an agency of the United States Government. Neither the United States Government nor any agency Thereof, nor any of their employees, makes any warranty, express or implied, or assumes any legal liability or responsibility for the accuracy, completeness, or usefulness of any information, apparatus, product, or process disclosed, or represents that its use would not infringe privately owned rights. Reference herein to any specific commercial product, process, or service by trade name, trademark, manufacturer, or otherwise does not necessarily constitute or imply its endorsement, recommendation, or favoring by the United States Government or any agency thereof. The views and opinions of authors expressed herein do not necessarily state or reflect those of the United States Government or any agency thereof. 


\section{DISCLAIMER}

Portions of this document may be illegible in electronic image products. Images are produced from the best available original document. 


\section{LEGAL NOTICE}

This report was prepared as an account of Government sponsored work. Neither the United States, nor the Commission, nor any person acting on behalf of the Commission:

A. Makes any warranty or representation, expressed or implied, with respect to the accuracy, completeness, or usefulness of the information contained in this report, or that the use of any information, apparatis, method, or process disclosed in this report may not infringe privately owned rights; or

B. Assumes any liabilities with respect to the use of, or for damages resulting from the use of any information, apparatus, method, or process disclosed in this report.

As used in the above, "person acting on behalf of the Commission" includes any employee or contractor of the Commission, or employee of such contractor, to the extent that such employee or contractor of the Commission, or employee of such contractor prepares, disseminates, or provides access to, any information pursuant to his employment or contract with the Commission, or his employment with such contractor.

This report expresses the opinions of the author or authors and does not necessarily reflect the opinions or views of the Los Alamos Scientific Laboratory.

Printed in the United States of America. Available from Clearinghouse for Federal Scientific and Technical Information National Bureau of Standards, U. S. Department of Commerce

Springfield, Virginia 22151

Price: Printed Copy $\$ 3.00 ;$ Microfiche $\$ 0.65$ 


\section{LOS ALAMOS SCIENTIFIC LABORATORY of the University of California LOS ALAMOS - NEW MEXICO}

Report written: September 1967

Report distributed: March 12, 1968

\section{Integral-Transform Lie-Series}

\section{Analysis of Transient Temperatures in Reactor Coolant Channels}

by

Roy Arthur Axford

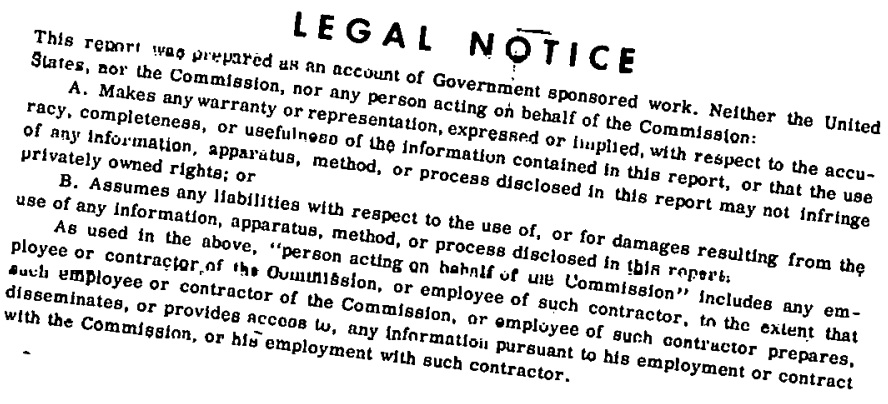




\section{CONTENTS}

\section{$\Lambda$ bstract}

1. Introduction

2. Mathematical Formulation

3. Initial Steady-State Solutions

4. Hanke1-Transform Reduction of Partial-Differential Energy $\mathrm{Bal}$ ances to a System of Ordinary Differential Equations

5. Lie-Series Computational Algorithm

6. Allowance for Heat-Transfer Coefficient Strongly Dependent on Coolant Speed

7. Function Subprograms Required for LIETRAN 


\title{
INTEGRAL-TRANSFORM LIE-SERIES ANALYSIS \\ OF TRANSIENT TEMPERATURES \\ IN REACTOR COOLANT CHANNELS
}

by

Roy Arthur Axford*

ABSTRACT

\begin{abstract}
A new method is develoned for computing transient tcmperature fields in cylindrical reactor channel's when the relative fuel power density, the coolant speed, and the channel inlet temperature are arbitrarily specified functions of time. Through the use of Hankel transforms, numerical instabilities inherent in finite difference approximations of spatial derivatives are avidied. Solutions of high order systems of ordinary differential equations in the time coordinate are efficiently obtained by a computational algorithm based upon the concept of Lie series.
\end{abstract}

\section{Introduction}

Preventing numerical instabilities in the temperature calculations can be the contrulling factor in the efficiency of reactor dynamics calculations with feedbacks. This is particularly true as the temperature model becomes more detailed.

In this study, a method is developed for analyzing transient temperature fields in cylindrical reactur channels. Finite diffcrence approximations to the spatial derivatives in the fundamental energy balances are not used, and inherent numerical instabilities are, thereby, avoided.

\section{Mathematical Formulation}

If axial heat conduction in the fue 1 is neglected and the fuel themal properties are assumed constant, then the fuel-region temperature satisfies

$\frac{1}{\alpha} \frac{\partial}{\partial t} v(r, z, t)=\frac{1}{r} \frac{\partial}{\partial r}\left[r \frac{\partial}{\partial r} v(r, z, t)\right]+\frac{1}{k} Q(r, z, t)$

in the case of cylindrical fuel rods. Let $v_{j}(r, t)$ *The author, a professor at the Nuclear Engineering. Laboratory, University of Illinois, Urbana, Illinois, is a consultant to the Los Alamos Scientific Laboratory. be defined as the average fuel temperature over the jth axial segment with length $\Delta z_{j}$; i.e.,

$$
v_{j}(r, t)=\frac{1}{\Delta z} \int_{z_{j}}^{z} j+1 d z v(r, z, t) .
$$

When Eq. 1 is averaged over the $j$ th axial segment, it follows that

$\frac{1}{a} \frac{\partial}{\partial t} v_{j}(r, t)$

$=\frac{1}{r} \frac{\partial}{\partial r}\left[r \frac{\partial}{\partial r} v_{j}(r, t)\right]+\frac{1}{k} \frac{1}{\Delta z} \int_{z_{j}}^{z} j+1 d z Q(r, z, t)$.

If $\zeta(z)$ is the nondimensional relative power shape in the axial direction, so that the fuel power density takes the form,

$$
Q(r, z, t)=Q(r, t) \zeta(z),
$$

then the integral in Eq. 2 may be written as

$$
\frac{1}{\Delta z} \int_{z_{j}}^{z}{ }^{j+1} d z Q(r, z, t)=A_{j} Q(r, t),
$$

in whish the definition

$$
A_{j}=\frac{1}{\Delta z} \int_{z_{j}}^{z} d z \zeta(z)
$$


has been introduced. Accordingly, Eq. 3 reduces to

$\frac{1}{\alpha} \frac{\partial}{\partial t} v_{j}(r, t)=\frac{1}{r} \frac{\partial}{\partial r}\left[r \frac{\partial}{\partial r} v_{j}(r, t)\right]+\frac{A_{j}}{k} Q(r, t)$.

Equation 7 is the energy balance for the average fuel temperature in the $j$ th axial segment at radial position $r$ and time $t$.

The axial power shape coefficient, $A_{j}$, defined by Eq. 6 may be interpreted as follows. If we assume that the active fuel region is defined by the closed interval, $-\mathrm{L} \leq \mathrm{z} \leq \mathrm{L}$, so that $2 \mathrm{~L}$ is the active fuel length, then the average-to-peak axial power ratio, $P$, is given by

$$
P=\frac{1}{2 L} \int_{-L}^{L} d z \zeta(z) \text {. }
$$

Since

$$
\int_{-L}^{L} d<\zeta(L)=\sum_{j=1}^{J} \int_{z j}^{z} j+1 d z \zeta(z),
$$

in which $\mathrm{J}$ is the number of subintervals into which the active fue 1 interval is partitioned, it follows from Eqs. 8, 9, and 6 that

$$
P=\frac{1}{2 L} \sum_{j=1}^{J} A_{j} \Delta z_{j} \text {. }
$$

Accordingly, the axial power shape coefficient, $A_{j}$, is the ratio of the average power generated in the $j$ th axial segment to the peak power in the active fuel region.

In the case of a parabolic axial power shape symmetric about the center plane as defined by

$\zeta(z)=1-(\dddot{1}-\varepsilon)\left(\frac{z}{L}\right)^{2},(-L \leq z \leq L)$,

in which $\varepsilon$ is the axial edge-to-peak power ratio, the axial power shape coefficient takes the form

$A_{j}=1-\frac{(1-\varepsilon)}{3}\left[\left(\frac{z_{j+1}}{L}\right)^{2}+\left(\frac{z_{j+1}}{L}\right)\left(\frac{z_{j}}{L}\right)+\left(\frac{z_{j}}{L}\right)^{2}\right]$.

The axial positions, $z_{j}$, appearing in Eq. 12 are given by

$z_{j}=-L+\frac{(j-1)}{J} 2 L \quad, \quad(j=1,2, \ldots, J+1)$,

when the active fuel region is arbitrarily divided into $\mathrm{J}$ equal axial segments.

If axial heat conduction is neglected, the bulk mean coolant temperature, $T(z, t)$, satisfies $\rho_{c} c_{p c} A_{F} \frac{\partial}{\partial t} \dot{T}(z, t)+\rho_{c} c_{p c} A_{F} u_{0} u(t) \frac{\partial}{\partial z} T(z, t)$

$$
=-k 2 \pi a \frac{\partial}{\partial r} v(a, z, t) \text {, }
$$

in which $u_{0}$ is the initial coolant speed and $u(t)$ is the relative coolant speed. In Eq. $14, A_{F}$ is the flow area. Let

$$
T_{j}(t)=\frac{1}{\Delta z} \int_{z_{j}}^{z} j+1 d z T(z, t)
$$

be the average bulk mean coolant temperature over the $j$ th axial segment; then averaging Eq. 14 over the $j$ th axial segment yields

$\rho_{c} c_{p c} A_{F} \frac{d}{d t} T_{j}(t)$

$+\rho_{r} c_{p r} A_{F} u_{n} u(t) \frac{1}{\Delta \varepsilon_{j}} \int_{z_{j}}^{z} j+1 d z \frac{\partial}{\partial \Sigma} T(z, t)$

$=-2 \pi a k \frac{\partial}{\partial r} v_{j}(a, t)$.

The integral in Eq. 16 takes the form,

$\frac{1}{\Delta z_{j}} \int_{z_{j}}^{z}{ }^{j+1} d z \frac{\partial}{\partial z} T(z, t)=\frac{1}{\Delta z_{j}}\left[T\left(z_{j+1}, t\right)-T\left(z_{j}, t\right)\right]$,

in which

$T\left(z_{j+1}, t\right)=$ outlet temperaturc of $j$ th axial segment, and

$T\left(z_{j}, t\right)$ - inlot temperature of $j$ ll axlal segment.

When the z-dependence of the bulk mean coolant temperature in the $j$ th axial segment is approximated by a linear interpolation,

$T(z, t)=\frac{\left(z_{j 11}-z\right)}{\Delta z_{j}} T\left(z_{j}, t\right)+\frac{\left(z-z_{j}\right)}{\Delta z_{j}} T\left(z_{j+1}, t\right)$,

for $z_{j} \leq z \leq z_{j+1}$, we find from Eq. 15 that

$$
T\left(z_{j+1}, t\right)=2 T T_{j}(t)-T\left(z_{j}, t\right) .
$$

From Eqs. 16, 17, and 19 it follows that

$$
\begin{aligned}
& \rho_{c} c_{p c} A_{F} \frac{d}{d t} T_{j}(t) \\
& +\rho_{c} c_{p c} A_{F} u(t) \frac{2 u_{n}}{\Delta z_{j}}\left[T_{j}(t)-T\left(z_{j}, t\right)\right] \\
& =-2 \pi a k \frac{\partial}{\partial r} v_{j}(a, t) .
\end{aligned}
$$


Equation 20 is the basic energy balance for the average bulk mean coolant temperature in the $j$ th axial segment in terms of the inlet temperature to that segment, the relative coolant speed under variable coolant flow conditions, and the heat input to the coolant from the fuel.

The fuel energy balance, Eq. 1, and the coolant energy balance, Eq. 14, are coupled by the boundary condition,

$$
-k \frac{\partial}{\partial r} v(a, z, t)=H[v(a, z, t)-T(z, t)] .
$$

Averaging Eq. 21 over the $j$ th axial segment gives

$$
-k \frac{\partial}{\partial r} v_{j}(a, t)=H\left[v_{j}(a, t)-T_{j}(t)\right] \text {. }
$$

In Eq. $22 \mathrm{H}$ is an effective heat-transfer coefficient that takes into account the thermal resist.ances of the cladding wall and the thermal bond between the fuel region and the cladding. The effective heat transfer coefficient is, in general, a function of time, since the coolant speed is regarded as an arbitrary function of time. We will first assume that the effective heat-transfer coefficient is a weak function of the coolant speed as in the case of liquid metal coolants. It is discussed as a strong function of coolant speed in Section 6 .

Let $Q_{0}$ be the maximum power density in the fuel region. Then the power density appearing in Eq. 7 becomes

$$
Q(r, t)=Q_{0} q(r, t) \text {, }
$$

in which $q(r, t)$ is the nondimensional relative power density at time $t$. In Eqs. 7, 20, and 22, replacing the time variable by the nondimensional time, $\alpha t / a^{2}$, and the radial fuel coordinate by $r / a$ gives for the energy balances the following forms in which the independent variables are nondimensional:

$$
\begin{aligned}
\frac{\partial}{\partial t} v_{j}(r, t)= & \frac{1}{r} \frac{\partial}{\partial r} \cdot\left[r \frac{\partial}{\partial r} v_{j}(r, t)\right]+s_{j} q(r, t), \\
\frac{d}{d t} T_{j}(t) & +u_{j} u(t) T_{j}(t)=u_{j} u(t) T\left(z_{j}, t\right) \\
& +f 2 \eta \frac{\rho c_{p}}{\rho_{c} c_{p c}}\left[v_{j}(1, t)-T_{j}(t)\right],
\end{aligned}
$$

and

$$
-\frac{\partial}{\partial r} v_{j}(1, t)=n\left[v_{j}(1, t)-I_{j}(t)\right] .
$$

Equations $24-26$ are valid for $j=1,2, \ldots, J$ and for $0 \leq r \leq 1$. In Eqs. $24-26$ the following definitions. have been introduced:

$$
\begin{aligned}
n & \equiv a H / k, \\
s_{j} & \equiv \frac{a^{2} Q_{0}}{k} A_{j}, \\
u_{j} & \equiv \frac{2 a^{2} u_{0}}{\alpha \Delta z},
\end{aligned}
$$

and

$$
f \equiv \frac{\pi a^{2}}{A_{F}} \text {. }
$$

Also, in Eq. 25 the gradient of the fuel temperature field evaluated at the outer edge of the fuel has been eliminated by means of Eq. 22. Equation 27 is the Biot number; Eq. 28 gives, in effect, the power generated in the $j$ th axial segment of the fue 1 ; and $\mathrm{Eq} .30$ is the fuel-to-coolant volume ratio.

\section{Initial Steady-State Solutions}

To specify the initial values of the unknown, axially averaged temperatures appearing in Eqs. 24 and 25 , the solutions of these equations are required for an initially specified, time-independent relative power density, $q_{0}(r)$. The initial steady state counterpart of Eqs. 24-26 assumes the form

$$
\begin{gathered}
\frac{1}{r} \frac{d}{d r}\left[\frac{d}{d r} v_{j}(r)\right]+s_{j} q_{0}(r)=0, \\
u_{j} T_{j, 0}=u_{j} T\left(z_{j}, 0\right)+f 2 n \frac{\rho c_{p}}{p_{c} c_{p c}}\left[v_{j}(1)-T_{j, 0}\right],
\end{gathered}
$$

and

$$
-\frac{d}{d r} v_{j}(1)=\eta\left[v_{j}(1)-T_{j, 0}\right] \text {, }
$$

in which these definitions have been used:

$$
v_{j}(r)=\text { average fuel temperature in the } j \text { th }
$$
axial segment at the radial position, $\mathbf{r}$, $\mathrm{T}_{j, 0}=$ initial value of the average bulk mean coolant temperature in the $j$ th. axial segment, and

$$
T\left(z_{j}, 0\right)=\text { initial value of the coolant inlet }
$$

temperature to the $j$ th axial segment.

Exact and approximate solutions of Eqs. 31-33 will be computed. The approximate solution based upon the method of zero-order Hankel transforms provides the initial values of the Hankel transform required in solving the transient system, Eqs. 24-26. The exact, solution determines the accuracy of the Hankel transform solution of the initial steady-state problem as 
a function of the number of terms retained in the Hankel transform inversion theorem.

The exact solution of Eq. 31 subject to Eq. 33 under the assumption that radial flux depression in the fuel is neglected, so the $q_{0}(r)=1$, is found to be

$$
v_{j}(r)=T_{j, 0}+\frac{1}{2 \pi} s_{j}+\frac{1}{4} s_{j}\left(1-r^{2}\right),
$$

for $j=1,2,3, \ldots, J$. From Eqs. 32 and 34 it follows that

$$
T_{j, 0}=T\left(z_{j}, 0\right)+f \frac{\rho c p}{\rho_{c} c_{p c}} \frac{s_{j}}{u_{j}},
$$

for $j=1,2,3, \ldots . J$. Equation 35 gives the average bulk mean coolant temperature in the $j$ th axial segment in terms of the inlet temperature to that segment. From Eqs. 19 and 35 it follows that the outlet temperature of the $j$ th axial segment in the initial steady state is given by

$$
T\left(z_{j+1}, 0\right)=T\left(z_{j}, 0\right)+2 f \frac{\rho c}{\rho c c_{p c}} \frac{s_{j}}{u_{j}},
$$

for $J=1,2, \ldots, J$.

$$
v_{j}\left(n_{i}\right)=\int_{0}^{l} d r r J_{0}\left(n_{i} x\right) v_{j}(r)
$$

be defined as the zero-order Hankel transform of the $j$ th axial segment fuel temperature in the initial steady state. The constants, $n_{i}$, in Eq. 37 are yet to be defined. The zero-order Hankel transform of Ey. 31 yields.

$$
\begin{aligned}
-n_{i}^{2} v_{j}\left(n_{i}\right) & +J_{0}\left(n_{i}\right) \frac{d}{d r} v_{j}(1)+n_{i} J_{1}\left(n_{i}\right) v_{j}(1) \\
& +o_{j} q_{0}\left(n_{i}\right)=0,
\end{aligned}
$$

in which $q_{0}\left(n_{j}\right)$ is the Hankel transform of the radially dependent relative power density in the fuel. Eliminating the gradient of the fuel temperature field evaluated at the outer edge of the fuel from Eq. 38 by means of Eq. 33 produces

$$
\begin{aligned}
& -n_{i}^{2} v_{j}\left(n_{i}\right)+\eta J_{0}\left(n_{i}\right) T_{j, 0} \\
& +v_{j}(1)\left[n_{i} J\left(n_{i}\right)-n J_{0}\left(n_{i}\right)\right]+s_{j} q_{0}\left(n_{i}\right)=0 .
\end{aligned}
$$

The requirement that the constants, $n_{i}$, are to be the zeros of the transcendental equation,

$$
n_{i} J_{1}\left(n_{i}\right)-n_{0}\left(n_{i}\right)=0,
$$

leads to the following result for the Hankel transform:

$$
v_{j}\left(n_{i}\right)=\frac{\eta}{n_{i}^{2}} J_{v}\left(n_{i}\right) T_{j, 0}+\frac{l}{n_{i}^{2}} s_{j} q_{0}\left(n_{i}\right) .
$$

Assume that the average fue 1 temperature in the jth axial segment may be represented by the FourierBessel series,

$$
v_{j}(r)=\sum_{i=1}^{\infty} A_{i, j} J_{0}\left(n_{i} r\right)
$$

The zero-order Hankel transform of $\mathrm{Eq} .42$ is

$$
v_{j}\left(n_{k}\right)=\sum_{i=1}^{\infty} A_{i, j} \int_{0}^{1} d r r J_{0}\left(n_{k} r\right) J_{0}\left(n_{i} r\right)
$$

Sinst

$$
\int_{0}^{1} d r r J_{0}\left(n_{k} r\right) J_{0}\left(n_{i} r\right)=\delta_{i k} \frac{1}{2 n_{i}^{2}}\left(n^{2}+n_{i}^{2}\right) J_{n}^{2}\left(n_{i}\right),
$$

in which $\delta_{i k}$ is the Kronecker delta when the constants, $n_{i}$, are the zeros of Eq. 40, it follows from Eqs. 43 and 44 that

$$
A_{1, j}=v_{j}\left(n_{i}\right) \frac{2 n_{i}^{2}}{\left(n^{2}+n_{i}^{2}\right) J_{0}^{2}\left(n_{i}\right)}
$$

Consequent ly ly. the Hankel-transform inversion thenrem takes the form

$$
v_{j}(r)=\sum_{i=1}^{\infty} \frac{2 n_{i}^{2}}{\left(n^{2}+n_{i}^{2}\right) J_{0}^{2}\left(n_{i}\right)} v_{j}\left(n_{i}\right) J_{0}\left(n_{i} r\right),
$$

when the constants, $n_{i}$, are the roots of Eq. 40 . Combining Eqs. 41 and 46 produces

$$
\begin{aligned}
v_{j}(r) & =l_{j, 0} \sum_{i=1}^{\infty} \frac{3 n}{\left(n^{2}+n_{i}^{2}\right)} \frac{J_{0}\left(n_{i} r\right)}{J_{0}\left(n_{i}\right)} \\
& +s_{j} \sum_{i=1}^{\infty} \frac{2 q_{0}\left(n_{i}\right)}{\left(n^{2}+n_{i}^{2}\right)} \frac{J_{0}\left(n_{i} r\right)}{J_{0}^{2}\left(n_{i}\right)} .
\end{aligned}
$$

A further simplification of Eq. 47 may be achieved by noting that the Fourier-Bessel series representation of unity is

$$
1=\sum_{i=1}^{\infty} \frac{2 n}{\left(n^{2}+n_{i}^{2}\right)} \frac{J_{0}\left(n_{i} r\right)}{J_{0}\left(n_{i}\right)}
$$

provided that the constants, $n_{i}$, are the zeros of Eq. 40. Thus, Eq. 47 reduces to 


$$
v_{j}(r)=T_{j, 0}+s_{j} \sum_{i=1}^{\infty} \frac{2 q_{0}\left(n_{i}\right)}{\left(n^{2}+n_{i}^{2}\right)} \frac{J_{0}\left(n_{i} r\right)}{J_{0}^{2}\left(n_{i}\right)} \text {, }
$$

which gives the fuel temperature field in the $j$ th axial segment in terms of the zero-order Hankel transform of the radial variation of the relative power density in the fuel.

In comparing the exact result computed from Eq. 34 and the approximate result computed from Eq. 49 when a finite number, $I$, of terms are kept in the summation, it will be seen that, when $q_{0}(r)=1$,

$$
q_{0}\left(n_{i}\right)=\frac{1}{n_{i}} J_{1}\left(n_{i}\right)
$$

so that, in view of Eq. 40 , Eq. 49 specializes down to

$$
v_{j}(r)=T_{j, 0}+s_{j} \sum_{i=1}^{I} \frac{2 \pi}{\left(n^{2}+n_{i}^{2}\right) n_{i}^{2}} \frac{J_{0}\left(n_{1} r\right)}{J_{0}\left(n_{i}\right)}
$$

in the case of a radially flat fuel power density. Results for the average fuel temperature field in the $j$ th axial segment computed from Eqs. 34 and 51 establish the number of terms required in the sum in Eq. 51 to obtain a specified number of significant digits in the approximate Hankel-transform solution for the initial steady-state fuel temperature.

Evaluating Eq. 51 at the outer edge of the fuel region and substituting the result in Eq. 32 gives the corresponding approximate solution,

$$
T_{j, 0}=T\left(z_{j}, 0\right)+2 n f \frac{\rho c p}{\rho_{c} c p c} \frac{s}{u_{j}} \sum_{i=1}^{I} \frac{2 n}{\left(n^{2}+n_{i}^{2}\right) n_{i}^{2}},
$$

for the axially averaged bulk mean coolant tcmpcrature in the $\mathrm{jth}$ axial scgment to be compared with Eq. 35. From Eqs. 19 and 52 it follows that

$$
T\left(z_{j+1}, 0\right)=T\left(z_{j}, 0\right)+4 n f \frac{\rho c_{p}}{\rho_{c} c_{p c}} \frac{s_{j}}{u_{j}} \sum_{i=1}^{I} \frac{2 n}{\left(n^{2}+n_{i}^{2}\right) n_{i}^{2}}
$$

is the approximate result for the cxit bulk mean r.nnlant temperature from the $j$ th axial segment which corresponds to the exact solution of Eq. 36 .

From the steady-state counterpart of Eq. 19

$$
T\left(\Sigma_{j+1}, 0\right)-3 T_{j, 0} T\left(B_{j}, 0\right) \text {, }
$$

it may be established by mathematical induction that

$$
T\left(z_{j}, 0\right)=2 \sum_{m=1}^{j-1}(-1)^{j+m+1} T_{m, 0}+(-1)^{j-1} T\left(z_{1}, 0\right),
$$

which is valid for $j=2,3,4, \ldots, J$, and in which $T\left(z_{1}, 0\right)$ is the initial value of the coolant inlet temperature to the channel. Equation 55 may be interpreted in two alternative ways. First, it may be thought of as giving the inlet temperature to the jth axial segment from the second segment on in terms of the inlet temperature to the entire channel and the average bulk mean coolant temperatures of the previous axial segments. If the index, $j=2,3,4$, $\ldots \ldots, \mathrm{J}+1$, then Eq. 55 is to be interpreted as providing the outlet temperature from the $(j-1)$ st axial segment in terms of the channel inlet temperature and the average bulk mean temperatures of all previous axial segments including the segment for which the outlet bulk mean coolant temperature is being computed. An alternative consistency check on the coolant outlet temperatures from the various axial segments is afforded by Eq. 55 .

4. Hankel-Transform Reduction of Partial-Differential Energy Balances to a System of Ordinary Differential Equations

The system of equations embodied in the energy balances of Eqs. 24-26 comprises a coupled set of partial and ordinary differential equations for the average fuel and bulk mean coolant temperatures in the $j$ th axial segment. By removing the radial spatial dependence from Eq. 24 by introducing the transient Hankel transform of the fue 1 temperature field in the $j$ th axial segment, Eqs. 24-26 may be reduced to a system of pure differential equations together with subsidiary algebraic equations.

Let

$$
v_{j}\left(n_{i}, t\right)=\int_{0}^{l} d r \quad J_{0}\left(n_{i} r\right) v_{j}(r, t)
$$

be the zero-order Hankel transform of the transient fuel temperature field in the $j$ th axial segment. The Hankel transform of $\mathrm{Eq} .24$ is

$$
\begin{aligned}
\frac{d}{d t} v_{j}\left(n_{j}, t\right) & =-n_{i}^{2} v_{j}\left(n_{i}, t\right)+J_{0}\left(n_{i}\right) \frac{\partial}{\partial r} v_{j}(1, t) \\
& +n_{i} J_{1}\left(n_{i}\right) v_{j}(1, t)+s_{j} q\left(n_{i}, t\right),
\end{aligned}
$$

in which

$$
y\left(n_{i}, t\right)=\int_{0}^{l} d r r J_{0}\left(n_{i} r\right) \varphi(r, l)
$$

is the Hankel transform of the radially dependent 
relative power density. When the radial flux depression in the fuel region is neglected, Eq. 58 specializes to

$$
q\left(n_{i}, t\right)=\frac{1}{n_{i}} J_{1}\left(n_{i}\right) q(t),
$$

wherein $q(t)$ is the time-dependent relative power density such that $q(0)=1$. The elimination of the radial gradient of the fuel temperature field in Eq. 57 by means of Eq. 26 brings Eq. 57 into the form,

$$
\begin{aligned}
\frac{d}{d t} v_{j}\left(n_{i}, t\right) & =-n_{i}^{2} v_{j}\left(n_{i}, t\right) \\
& +v_{j}(1, t)\left[n_{i} J_{1}\left(n_{i}\right)-n J_{0}\left(n_{i}\right)\right] \\
& +n J_{0}\left(n_{i}\right) T_{j}(t)+s_{j} q\left(n_{i}, t\right) .
\end{aligned}
$$

The second term on the right-hand side of Eq. 60 drops out, provided that the constants, $n_{i}$, are taken as the zeros of Eq. 40 as in the steady-state case. Accordingly, Eq. 60 can be simplified to

$$
\begin{aligned}
& \frac{d}{d t} v_{j}\left(n_{i}, t\right) \\
= & -n_{i}^{2} v_{j}\left(n_{i}, t\right)+n J_{0}\left(n_{i}\right) T_{j}(t)+s_{j} q\left(n_{i}, t\right) .
\end{aligned}
$$

In view of Eqs. 40 and 59, Eq. 61 hecomes

$$
\begin{gathered}
\frac{d}{d t} v_{j}\left(n_{i}, t\right) \\
=-n_{i}^{2} v_{j}\left(n_{i}, t\right)+n J_{0}\left(n_{i}\right) T_{j}(t)+s_{j} q(t) \frac{n_{1}}{n_{i}^{2}} J_{0}\left(n_{i}\right)
\end{gathered}
$$

for the case of a radially flat relative fuel power density.

Let $D_{j}(t)$ be defined as the temperature drop from the outer edge of the fuel region to the bulk mean coolant temperature in the $j$ th axial segment; i $P$,

$$
D_{j}(t)=v_{j}(1, t)-T_{j}(t) .
$$

Under transient conditions the Hankel-transform inversion theorem corresponding to Eq. 46 is

$$
v_{j}(r, t)=\sum_{i=1}^{\infty} \frac{2 n_{i}^{2}}{\left(n^{2}+n_{i}^{2}\right) J_{0}^{2}\left(n_{i}\right)} v_{j}\left(n_{i}, t\right) J_{0}\left(n_{i} r\right) \text {. }
$$

With Eq. 64, Eq. 63 becomes

$$
D_{j}(t)=\sum_{i=1}^{\infty} \frac{2 n_{i}^{2} v_{j}\left(n_{i}, t\right)}{\left(n^{2}+n_{i}^{2}\right) J_{0}\left(n_{i}\right)}-T_{j}(t) .
$$

The series in Eq. 65 consists, in fact, of the sum of two series, which may be seen as follows.
Consider the situation in which the Hankel transform is changing slowly enough with time so that its derivative is approximately zero. Under these conditions Eq. 62 rearranges to

$$
v_{j}\left(n_{i}, t\right) \triangleq \frac{n J_{0}\left(n_{i}\right)}{n_{i}^{2}} T_{j}(t)+s_{j} q(t) \frac{n}{n_{i}^{4}} J_{0}\left(n_{i}\right) .
$$

Combining Eqs. 65 and 66 gives

$$
\begin{aligned}
D_{j}(t) & \triangleq T_{j}(t) \sum_{i=1}^{\infty} \frac{2 n}{n^{2}+n_{i}^{2}} \\
& +s_{j} q(t) \sum_{i=1}^{\infty} \frac{2 n}{\left(n^{2}+n_{j}^{2}\right) n_{i}^{2}}-T_{j}(t)
\end{aligned}
$$

during slow transients. Of the two summations in Eq. 67, that in the first term on the right converges much less rapidly than that in the second term. This is particularly true for large values of the Biot number. However, the summation of the first term equals unily, so the flrst and third terms on the right cance1. Consequently, the temperature drop from the outer edge of the fuel to the bulk mean coolant temperature is, in fact, represented by the morc rapidly converging series.

To cancel out the more slowly converging series when tlie llaukel lrausfurlll 1 s compured by solving ta. 62 , whether it is changing slowly or rapidly with time, the temperature drnp from the outer edge of the fuel to the bulk mean coolant tcmpcrature is writren as

$$
D_{j}(t)=\sum_{i=1}^{I} \frac{2 n_{i}^{2} v_{j}\left(n_{i}, t\right)}{\left(n^{2}+n_{i}^{2}\right) J_{0}\left(n_{i}\right)}-T_{j}(t) \sum_{i=1}^{I} \frac{2 \eta}{n^{2}+n_{i}^{2}},
$$

in which the fact that a finite number, $I$, of terms are recalned in the Hankel transform inversion theorem is indicated.

In view of $\mathrm{Eq} .63$, the coolant energy balance of Eq. 25 becomes

$$
\begin{aligned}
\frac{d}{d t} T_{j}(t) & +u_{j} u(t) T_{j}(t) \\
& =u_{j} u(t) I^{\prime}\left(z_{j}, t\right)+f 2 \eta \frac{\rho c p}{\rho_{c} c_{p c}} D_{j}(t) .
\end{aligned}
$$

Equations 69 and 62 (or Eq. 61 if the radial flux depression in the fuel region is taken into account) are to be regarded as a system of $(I+1) \mathrm{J}$ ordinary, 
first-order differential equations which govern the temporal behavior of the Hankel transforms, $v_{j}\left(n_{i}, t\right)$, of the fuel temperature field and the average bulk mean coolant temperature, $T_{j}(t)$, in the $j$ th axial segment. When $j=1$, Eq. 69 contains the time dependence of the inlet temperature to the channel, which is also an arbitrarily specified function of time, in addition to the relative coolant speed, $u(t)$, and relative power density, $q(t)$. There are an additional $2 \mathrm{~J}$ unknown functions, namely, the bulk mean coolant outlet temperatures, $T\left(z_{j+1}, t\right)$, from each axial segment and the temperature drops, $D_{j}(t)$, from the outer edge of the fuel to the bulk mean conlant. temperature in each axial segment. An additional $2 J$ rolations for these quantitips are contained in Eqs. 19 and 68.

Accordingly, the time dependence of $v_{j}\left(n_{i}, t\right)$, $T_{j}(t), D_{j}(t)$, and $T\left(z_{j+1}, t\right)$ is governed by a combined system of $(I+3) J$ algebraic and first-order differential equations. The initial values of the average bulk mean coolant temperature in the $j$ th axial segment are provided by Eq. 52; that of the exit bulk mean coolant temperature from the $j$ th axial segment, by Eq. 53; and that of the Hankel transform of the fuel region temperature field, by Eq. 41, for an arbitrary radial variation of the relative power density in the fuel. The initial values of the temperature drops from the outer fuel edge to the coolant are computed from Eq. 49 or 51 for an arbitrary radial variation in the relative fuel power density or for a flat radial variation, respectively. For example, from Eq. 51

$$
D_{j}(0)=s_{j} \sum_{i=1}^{I} \frac{2 n}{\left(n^{2}+n_{i}^{2}\right) n_{i}^{2}} .
$$

Note that the initial values of the unknown temporal functions are computed from the approximate Hankeltransform solution of the initial steady-state problem. The use of initial values calculated from the exact steady-state solution does not lead to a more accurate solution for the transient problem. The accuracy of the transient problem is controlled, in part, by the number of terms in the Hankel-transform Inversion theorem, and further, by the convergence criterion placed on the Lie series.

\section{Lie-Series Computational Algorithm}

In the previous sections fundamental fuel region and coolant energy balances, Eqs. 1 and 16, have been reduced to a system of first-order, ordinary, differential equations with subsidiary algebraic equations. The solution of this system is sought on the $k$ th time interval such that $t_{k} \leq t \leq t_{k+1}$. To denote the fact that a computational algorithm is developed for the $k$ th time interval, which is arbitrary, an additional subscript, $k$, will be added to all unknown functions. Consequently, the basic system of $(\mathrm{I}+3) \mathrm{J}$ linear algebraic and ordinary differential equations under consideration is

$$
\begin{aligned}
& \frac{d}{d t} v_{j, k}\left(n_{i}, t\right)=-n_{i}^{2} v_{j, k}\left(n_{i}, t\right) \\
& +n J_{n}\left(n_{i}\right) T_{j, k}(t)+s_{j} q(t) \frac{n}{n_{i}^{2}} J_{0}\left(n_{i}\right), \quad(71) \\
& \frac{d}{d t} T_{j, k}(t)+u_{j} u(t) T_{j, k}(t) \\
& =u_{j} u(t) T_{k}\left(z_{j}, t\right)+f 2 n \frac{\rho c_{p}}{\rho_{c} c_{p c}} D_{j, k}(t), \quad(72) \\
& D_{j, k}(t)=\sum_{i=1}^{I} \frac{2 n_{i}^{2} v_{j, k}\left(n_{i}, t\right)}{\left(n^{2}+n_{i}^{2}\right) J_{0}\left(n_{i}\right)}-T_{j, k}(t) \sum_{i=1}^{I} \frac{2 n}{n^{2}+n_{i}^{2}},
\end{aligned}
$$

and

$$
T_{k}\left(z_{j+1}, t\right)=2 T_{j, k}(t)-T_{k}\left(z_{j}, t\right),
$$

all of which are valid for $j+1,2,3, \ldots, J$. Also, Eq. 71 holds for $i=1,2,3, \ldots, I$. A numerical computational algorithm to produce the Lie-series* representations of the solution of the above system will now be obtained.

On the kth time interval, the Hankel transform of the fuel temperature field is expanded in the form,

$$
v_{j, k}\left(n_{i}, t\right)=v_{j, k}^{0}\left(n_{i}, t\right)+\sum_{v=1}^{\infty} v_{j, k}^{v}\left(n_{i}, t\right) ;
$$

the average bulk mean coolant temperature in the $j$ th axial segment, as

$$
T_{j, k}(t)=T_{j, k}^{0}(t)+\sum_{\nu=1}^{m} T_{j, k}^{\nu}(t) ;
$$

the temperature drop from the outer fuel edge to the coolant, as

*Wolfgang Gröbner, "Die Lie-Reihen und Ihre Anwendungen," Deutscher Verlag der Wissenschaften, Berlin, 1960 . 


$$
D_{j, k}(t)=D_{j, k}^{0}(t)+\sum_{v=1}^{\infty} D_{j, k}^{v}(t) ;
$$

and the outlet temperature of the $j$ th axial segment, as

$$
T_{k}\left(z_{j+1}, t\right)=T_{k}^{0}\left(z_{j+1}, t\right)+\sum_{v=1}^{\infty} T_{k}^{v}\left(z_{j+1}, t\right) .
$$

The first terms in Eqs. $75-78$ are to be interpreted as the values of the unknown functions at the beginning of the kth time interval. That is,

$$
\begin{aligned}
& v_{j, k}^{0}\left(n_{i}, t\right)=v_{j, k}\left(n_{i}, t_{k}\right), \\
& T_{j, k}^{0}(t)=T_{j, k}\left(t_{k}\right), \\
& D_{j, k}^{0}(t)=D_{j, k}\left(t_{k}\right),
\end{aligned}
$$

and

$$
T_{k}^{0}\left(z_{j+1}, t\right)=T_{k}\left(z_{j+1}, t_{k}\right) .
$$

The vth-order terms in Eqs. $75-78$ are defined as

$$
\begin{aligned}
& v_{j, k}^{v}\left(n_{i}, t\right)=\frac{\left(t-t_{k}\right)^{v}}{v !} \frac{d^{\nu}}{d t^{v}} v_{j, k}\left(n_{i}, t_{k}\right), \\
& T_{j, k}^{v}(t)=\frac{\left(t-t_{k}\right)^{v}}{v !} \frac{d^{v}}{d t^{v}} T_{j, k}\left(t_{k}\right), \\
& D_{j, k}^{\nu}(t)=\frac{\left(t-t_{k}\right)^{\nu}}{v !} \frac{d^{\nu}}{d t^{v}} D_{j, k}\left(t_{k}\right),
\end{aligned}
$$

and

$$
T_{k}^{\nu}\left(z_{j+1}, t\right)=\frac{\left(t-t_{k}\right)^{\nu}}{\nu !} \frac{d^{\nu}}{d t^{\nu}} T_{k}\left(z_{j+1}, t_{k}\right) .
$$

To determine the higher order terms in the Lieseries representations of Eqs. 75-78, the different1a1 and algebraic relations of Eqs. $71-74$ are transformed into a set of two-term recurrence relations. Differentiating Eq. $71 v-1$ times and evaluating the result at the beginning of the kth time interval gives

$$
\begin{gathered}
\frac{d^{\nu}}{d t^{\nu}} v_{j, k}\left(n_{i}, t_{k}\right)=-n_{i}^{2} \frac{d^{v-1}}{d t^{v-1}} v_{j, k}\left(n_{i}, t_{k}\right) \\
+n J_{0}\left(n_{i}\right) \frac{d^{v-1}}{d t^{v-1}} T_{j, k}\left(t_{k}\right)+s_{j} q_{v-1}\left(t_{k}\right) \frac{\eta}{n_{i}^{2}} J_{v}\left(n_{i}\right),
\end{gathered}
$$

in which $q_{v-1}\left(t_{k}\right)$ is the $(v-1)$ st time derivative of the relative power density at the beginning of the $k$ th time interval. Removing the Hankel trans- form and bulk coolant temperature derivatives from Eq. 87 by Eqs. 83 and 84 yields the recurrence relation,

$$
\begin{aligned}
& v_{j, k}^{v}\left(n_{i}, t\right)=-n_{i}^{2} \frac{\left(t-t_{k}\right)}{v} v_{j, k}^{v-1}\left(n_{i}, t\right) \\
&+n J_{0}\left(n_{i}\right) \frac{\left(t-t_{k}\right)}{v} T_{j, k}^{v-1}(t) \\
&\left.+\frac{\left(t-t_{k}\right)^{v}}{v !} s_{j} n \frac{J_{0}\left(n_{i}\right)}{n_{i}^{2}} q_{v-1}\left(t_{k}\right), v=1,2,3, \ldots\right),
\end{aligned}
$$

valid on the kth time interval. By the same procedure, the recurrence relations which are equivalent to Eqs. 73 and 74 , respectively, are found to be

$$
\begin{gathered}
D_{j, k}^{v}(t)=-T_{j, k}^{\nu}(t) \sum_{i=1}^{I} \frac{2 n}{n^{2}+n_{i}^{2}} \\
+\sum_{i=1}^{I} \frac{2 n_{i}^{2} v_{j, k}^{\nu}\left(n_{i}, t\right)}{\left(n^{2}+n_{i}^{2}\right) J_{0}\left(n_{i}\right)},(v=1,2,3, \ldots)
\end{gathered}
$$

and

$T_{k}^{v}\left(z_{j+1}, t\right)=2 T_{j, k}^{v}(t)-T_{k}^{v}\left(z_{j}, t\right),(\nu=1,2,3, \ldots)$.

In deriving the recurrence relation which corresponds to Eq. 72 , the fact that the relative coolant speed and the channel inlet temperature are both regarded as arbitrary functions of time must be considered. The $(v-1)$ st derivative of Eq. 72 at $t=t_{k}$ is

$$
\begin{aligned}
\frac{d^{\nu}}{d t^{\nu}} T_{j, k}\left(t_{k}\right)= & -\left.u_{j} \frac{d^{v-1}}{d t^{\nu-1}}\left[u(t) T_{j, k}(t)\right]\right|_{t=t_{k}} \\
& +\left.u_{j} \frac{d^{\nu-1}}{d t^{v-1}}\left[u(t) T_{k}\left(z_{j}, t\right)\right]\right|_{t-t_{k}} \\
& +f 2 n \frac{\rho c p}{\rho c c} \frac{d^{v-1}}{d t^{v-1}} D_{j, k}\left(t_{k}\right) .
\end{aligned}
$$

From Liebnitz's rule for differentiating the product. of two funcliuns, it follows that

$$
\begin{aligned}
& \left.\frac{d^{v-1}}{d t^{v-1}}\left[u(t) T_{j, k}(t)\right]\right|_{t=t_{k}} \\
= & \sum_{m=0}^{v-1} \frac{(v-1) !}{(v-1-m) ! m !} \frac{d^{v-1-m}}{d t^{v-1-m}} T_{j, k}\left(t_{k}\right) u_{m}\left(t_{k}\right),
\end{aligned}
$$

in which $u_{m}\left(t_{k}\right)$ is the mth derivative of the relative coolant speed at the beginning of the $k$ th time 
interval. In view of Eq. $84, \mathrm{Eq} .92$ reduces to

$$
\begin{aligned}
& \left.\frac{d^{\nu-1}}{d t^{\nu-1}}\left[u(t) T_{j, k}(t)\right]\right|_{t=t_{k}} \\
= & \sum_{m=0}^{v-1} \frac{(\nu-1) !}{m !} \frac{\left(t-t_{k}\right)^{m+1}}{\left(t-t_{k}\right)^{\nu}} T_{j, k}^{\nu-1-m}(t) u_{m}\left(t_{k}\right) .
\end{aligned}
$$

In the same way. it is found that

$$
\begin{aligned}
& \left.\frac{d^{v-1}}{d t^{v-1}}\left[u(t) T\left(z_{j}, t\right)\right]\right|_{t=t_{k}} \\
= & \sum_{m=0}^{v-1} \frac{(v-1) !}{m !} \frac{\left(t-t_{k}\right)^{m+1}}{\left(t-t_{k}\right)^{v}} T_{k}^{v-1-m}\left(z_{j}, t\right) u_{m}\left(t_{k}\right) .
\end{aligned}
$$

With Eqs. 84, 85, 93, and 94 the coolant energy balance of Eq. 91 simplifies to the recurrence relation,

$$
\begin{aligned}
& T_{j, k}^{v}(t)=-u_{j} \sum_{m=0}^{v-1} \frac{1}{v m !}\left(t-t_{k}\right)^{m+1} T_{j, k}^{v-1-m}(t) u_{m}\left(t_{k}\right) \\
& +u_{j} \sum_{m=0}^{v-1} \frac{1}{v m !}\left(t-t_{k}\right)^{m+1} T_{k}^{v-1-m}\left(z_{j}, t\right) u_{m}\left(t_{k}\right) \quad(95) \\
& +2 n f \frac{\rho c p}{\rho_{c} c_{p c}} \frac{\left(t-t_{k}\right)}{v} D_{j, k}^{v-1}(t),(v=1,2,3,4, \ldots),
\end{aligned}
$$

$$
\text { which is valid on the } \mathrm{kth} \text { time interval. Equations }
$$
$88,95,89$, and 90 comprise two-term recurrence relations for consecutive terms of the Lie-Series representations of the unknowns governed by Eqs. 71-74, respectively. To incorporate the initial steadystate solutions on the first time interval and the values of the Hankel. transform, hulk coolant temperatures, film temperature drops, and outlet temperatures of the $j$ th axial segment at the beginning of the kth time interval specifically into the recurrence relation formulation of Eqs. 88, 95, 89, and 90, these equations are written out explicity for the second and third terms in the Lie series, i.e., for $v=1$ and $v=2$.

The second terms of the Lie series of Eqs. 7578 for the $k$ th time interval are given by

$$
\begin{gathered}
v_{j, k}^{1}\left(n_{j}, t\right)=-n_{i, k}^{2}\left(t-t_{k}\right) v_{j, k}\left(n_{i,}, t_{k}\right) \\
+n J_{0}\left(n_{i}\right)\left(t-t_{k}\right) T_{j, k}\left(t_{k}\right)+\left(t-t_{k}\right) s_{j} \frac{J_{0}\left(n_{i}\right)}{n_{i}^{2}} q\left(t_{k}\right)
\end{gathered}
$$

and

$$
\begin{aligned}
T_{j, k}^{l}(t)= & -u_{j}\left(t-t_{k}\right) T_{j, k}\left(t_{k}\right) u\left(t_{k}\right) \\
& +u_{j}\left(t-t_{k}\right) T_{k}\left(z_{j}, t_{k}\right) u\left(t_{k}\right) \\
& +2 \eta f \frac{\rho c_{p}}{\rho_{c} c_{p c}}\left(t-t_{k}\right) D_{j, k}\left(t_{k}\right)
\end{aligned}
$$

together with Eqs. 89 and 90 with $v=1$. The third terms of the Lie series of Eqs. 75-78 are

$$
\begin{aligned}
v_{j, k}^{2}\left(n_{i}, t\right)= & -n_{i}^{2} \frac{\left(t-t_{k}\right)}{2} v_{j, k}^{1}\left(n_{i}, t\right) \\
& +\eta J_{0}\left(n_{i}\right) \frac{\left(t-t_{k}\right)}{2} T_{j, k}^{1}(t) \\
& +\frac{\left(t-t_{k}\right)^{2}}{2 !} s_{j} n \frac{J_{0}\left(n_{i}\right)}{n_{i}^{2}} q_{l}\left(t_{k}\right),
\end{aligned}
$$

and

$$
\begin{aligned}
T_{j, k}^{2}(t)= & -u_{j} \frac{\left(t-t_{k}\right)}{2} T_{j, k}^{l}(t) u\left(t_{k}\right) \\
& +u_{j} \frac{\left(t-t_{k}\right)}{2} T_{k}^{1}\left(z_{j}, t\right) u\left(t_{k}\right) \\
& -u_{j} \frac{\left(t-t_{k}\right)^{2}}{2} T_{j, k}\left(t_{k}\right) u_{1}\left(t_{k}\right) \\
& +u_{j} \frac{\left(t-t_{k}\right)^{2}}{2} T_{k}\left(z_{j}, t_{k}\right) u_{1}\left(t_{k}\right) \\
& +2 n f \frac{\rho c p}{\rho_{c} c p c} \frac{\left(t-t_{k}\right)}{2} D_{j, k}^{l}(t),
\end{aligned}
$$

along with Eqs. 89 and 90 with $\nu=2$. For the higher order terms in the Lie series such that $v=3,4,5$, $\ldots \ldots$, the recurrence relations of Eqs. 88-90 are conveniently coded as they stand, but the coolant energy balance recurrence relation in Eq. 95 is most directly coded by splitting off the $m=0$ and $\mathrm{m}=\nu-1$ terms under the summation, i.e., by coding 


$$
\begin{aligned}
& T_{j, k}^{v}(t)=-u_{j} \frac{\left(t-t_{k}\right)}{v} T_{j, k}^{v-1}(t) u\left(t_{k}\right) \\
&+u_{j} \frac{\left(t-t_{k}\right)}{v} T_{k}^{v-1}\left(z_{j}, t\right) u\left(t_{k}\right) \\
&-u_{j} \frac{\left(t-t_{k}\right)^{v}}{v !} T_{j, k}\left(t_{k}\right) u_{v-1}\left(t_{k}\right) \\
&+u_{j} \frac{\left(t-t_{k}\right)^{v}}{v !} T_{k}\left(z_{j}, t_{k}\right) u_{v-1}\left(t_{k}\right) \\
&-u_{j} \sum_{m=1}^{v-2} \frac{1}{v m !}\left(t-t_{k}\right)^{m+1} T_{j, k}^{v-1-m}(t) u_{m}\left(t_{k}\right) \\
&+u_{j} \sum_{m=1}^{v-2} \frac{1}{v m !}\left(t-t_{k}\right)^{m+1} T_{k}^{v-1-m}(z, t) u_{m}\left(t_{k}\right) \\
&+2 n f \frac{\rho c_{p}}{\rho c c_{p c}} \frac{\left(t-t_{k}\right)}{v} D_{j, k}^{v-1}(t),(v=3,4,5, \ldots)
\end{aligned}
$$

As written, Eq. 100 explicitly contains the bulk coolant temperatures, the inlet temperatures to the various axial segments, and the coolant speed at the beginning of the $k$ th time interval.

In practice the maximum number of terms which can be retained in the Lie series is set at a given, fixed input number, say $N$. The inequalities;

$$
\frac{\left|v_{j, k}^{N-1}\left(n_{i}, t_{k+1}\right)\right|+\left|v_{j, k}^{N}\left(n_{i}, t_{k+1}\right)\right|}{\left|v_{j, k}\left(1_{i}, t_{k+1}\right)\right|} \leq \varepsilon,
$$

$$
\frac{\left|T_{j, k}^{N-1}\left(t_{k+1}\right)\right|+\left|T_{j, k}^{N}\left(t_{k+1}\right)\right|}{\left|T_{j, k}{ }^{\left(t_{k+1}\right)}\right|} \leq \varepsilon,
$$

$$
\frac{\left|D_{j, k}^{N-1}\left(t_{k+1}\right)\right|+\left|D_{j, k}^{N}\left(t_{k+1}\right)\right|}{\left|D_{j, k}\left(t_{k+1}\right)\right|} \leq \varepsilon
$$

and

$$
\frac{\left|T_{k}^{N-1}\left(z_{j+1}, t_{k+1}\right)\right|+\left|T_{k}^{N}\left(z_{j+1}, t_{k+1}\right)\right|}{\left|T_{k}\left(z_{j+1}, t_{k+1}\right)\right|} \leq \varepsilon
$$

comprise the convergence tests applied to all of the Lie series at the end of the kth time interval for a specified error, $\varepsilon$. The denominators in Eqs. 101-104 are the current values of the unknowns as computed with $N$ terms in their Lie series. If the Lie series of any unknown in any axial segment fails to meet its convergence criterion in $N$ terms, the width of the time interval is reduced until all unknowns in every axial segment do meet their convergence tests. The maximum number of terms, $N$, to be allowed in the Lie series for a given time increment is set primarily by consideration of underflow in the particular computer employed. For the IBM-7094, the inequality $15 \leq N \leq 20$ gives representative values of the maximum allowable number of terms which can and need be carried in the Lie series for a given time increment. When the convergence critéria of Eqs. 101-104 are satistled in less than $\mathrm{N}$ terms, the computation is simply advanced to the next time interval with no change in time interval increment, which is reduced only if any of the unknown functions fails to converge within a maximum of $N$ terms reralned in their Lie series.

6. Allowance for Heat-Transfer Coefficient Strongly Dependent on Coolant Speed

The transient temperature field solutions so far obtained take into account arbitrary time variations in the relative power density, the coolant speed, and the channel inlet temperature under the restriction that the effective heat transfer coefficient is a weak function of the coolant speed. The time dependence of thc coolant speed, relative power density, and channel inlet temperature may be specified either analytically or numerically provided that the required derivatives for the lie series are known to sufficiently high order numerically.

When changes ill the effective heat transter coefficient are to be accounted for over the total time span during which the transient is followed, changes in the values of the roots of the transcendental relation, Eq. 40, have to be taken into account. Since relatively large changes in the effective heat transfer coefficient are required to produce small changes in the zeros of Eq. 40, it is not necessary to determine the zeros of Eq. 40 at every time step at which the transient temperatures are computed. Accordingly, the effective heat transfer coefficient may be assigned a constant value over each subinterval of a set into which the total time interval over which the transient is to be followed 
is partitioned. That is, the actual time variation of the effective heat transfer coefficient is approximated by a set of step functions. Let $\eta_{h}$ be the value of the Biot number on the $h$ th time subinterval such that $\tau_{h} \leq t \leq \tau_{h+1}$ for $h=1,2,3,4, \ldots$ and $\tau_{1}=0$. Note that subinterval partition in time for the effective heat transfer coefficient is not, in general, the same as the time subinterval partition which defines the points in time at which the transient temperature fields are computed. This latter partition is established primarily by the convergence criteria placed on the Lie-series representations of the transient temperature fields. Convergence of the Lie series is required regardless of the partitinn estahlished for the offective heat trancfor 80 efficient.

Since the effective heat-transfer coefficient is to be approximated by a set of step functions, it will be a discontinuous function in time. However, the transient temperature fields are continuous functions in time. Consequently, the key point in the approximate method under consideration is how to ensure time continuity in the transient temperature fields even though the heat-transfer coefficient is approximated discontinuously in time.

Let $n_{i}(k)$ be the ith root of $E q .40$ on the $k$ th time interval, $t_{k} \leq t \leq t_{k+1}$, and let $n_{1}(k-1)$ be the $i$ th rooc on the $(k-1) s t$ time interval,

$t_{k-1} \leq t \leq t_{k}$. Then, on the kth time interval, the transient fuel temperature field in the $j$ th axial segment is given by

$$
v_{j, k}(r, t)=\sum_{i=1}^{\infty} v_{j, k}\left[n_{i}(k), t\right] \frac{2 n_{i}^{2}(k)}{\left[n_{k}^{2}+n_{i}^{2}(k)\right]} \frac{J_{n}\left[n_{j}(k) r\right]}{J_{0}^{2}\left[n_{i}(k)\right]}
$$

and on the (k - 1)st interval, by

$$
\begin{aligned}
& v_{j, k-1}(r, t)=\sum_{i=1}^{\infty} v_{j, k-1}\left[n_{i}(k-1), t\right] \\
& \frac{2 n_{i}^{2}(k-1)}{\left[n_{k-1}^{2}+n_{i}^{2}(k-1)\right]} \frac{J_{0}\left[n_{i}(k-1) r\right]}{J_{0}^{2}\left[n_{i}(k-1)\right]}
\end{aligned}
$$

Since the fuel temperature is çontinuous at time $t=t_{k}$, it follows that

$$
v_{j, k}\left(r, t_{k}\right)=v_{j, k-1}\left(r, t_{k}\right) \text {. }
$$

By substituting Eqs. 105 and 106 into Eq. 107 and operating on the result with

$$
\begin{aligned}
& \int_{0}^{l} d r J_{0}\left[n_{m}(k) r\right] \text {, we find that } \\
& v_{j, k}\left[n_{m}(k), t_{k}\right] A_{m}(k) \int_{0}^{1} d r \dot{r} J_{0}^{2}\left[n_{m}(k) r\right] \\
& =\sum_{i=1}^{\infty} v_{j, k-1}\left[n_{i}(k-1), t_{k}\right] A_{i}(k-1) \\
& \int_{0}^{1} d r J_{0}\left[n_{m}(k) r\right] . J_{0}\left[n_{i}(k-1) r\right],
\end{aligned}
$$

in which the definition,

$$
A_{m}(k)=\frac{2 n_{m}^{2}(k)}{n_{k}^{2}+n_{m}^{2}(k)} \frac{1}{J_{0}^{2}\left[n_{m}(k)\right]}
$$

has been introduced. By noting that

$$
A_{m}(k) \int_{0}^{1} d r r J_{0}^{2}\left[n_{m}(k) r\right]=1,
$$

and that

$$
\begin{aligned}
& \int_{0}^{1} d r r J_{0}\left[n_{m}(k) r\right] J_{0}\left[n_{i}(k-1) r=\right. \\
= & \frac{1}{n_{m}^{2}(k)-n_{i}^{2}(k-1)}\left\{n_{m}(k) J_{0}\left[n_{i}(k-1)\right] J_{1}\left[n_{m}(k)\right]\right. \\
- & \left.n_{i}(k-1) J_{1}\left[n_{i}(k-1)\right] J_{0}\left[n_{m}(k)\right]\right\}
\end{aligned}
$$

we see that Eq. 108 reduces to

$$
\begin{aligned}
& v_{j, k}\left[n_{m}(k), t_{k}\right]=\sum_{i=1}^{\infty} v_{j, k-1}\left[n_{i}(k-1), t_{k}\right] A_{i}(k-1) \\
& \frac{1}{\left[n_{m}^{2}(k)-n_{i}^{2}(k-1)\right]} \times\left\{n_{m}(k) J_{0}\left[n_{i}(k-1)\right] J_{1}\left[n_{m}(k)\right]\right. \\
& \left.-n_{i}(k-1) J_{1}\left[n_{i}(k-1)\right] J_{0}\left[n_{m}(k)\right]\right\} .
\end{aligned}
$$

The following interpretation is to be placed on Eq. 112. At those points in time, $t_{k}$, at which the effective heat transfer coefficient is discontinuous, so that there is a change in value of the zeros of Eq. 40, the value of the Hankel transform at the beginning of the $k$ th time subinterval is to be computed from the value of the Hankel transform at the end of the $(k-1) s t$ time subinterval through 
Eq. 112. Thus, Eq. 112 serves to initiate the Hankel transform for the next time step at those points in time at which the effective heat transfer coefficient changes value discontinuously. This initiation ensures that the computed transient fuel region temperature field is a continuous function with respect to time.

The Hankel transform is initiated at time points for which there is no change in value of the effective heat transfer coefficient through the relation,

$$
v_{j, k}\left[n_{m}(k), t_{k}\right]=v_{j, k-1}\left[n_{m}(k-1), t_{k}\right]
$$

in which

$$
n_{11 !}(k)=n_{m !}(k-1) \text {. }
$$

since at such points there is no change in the values of roots of $\mathrm{Eq} .40$.

Even at points in time at which the effective heat transfer coefficient becomes discontinuous, the values of all other unknown temporal functions appearing in the system of Eqs. 71-74 at the end of the (k - 1)st time subinterval are equal to the values of these functions at the beginning of the kth time subinterval.

\section{Function Subprograms Required for LIETRAN}

'l'he Fortran listing of the main program of an IBM-7094 computer code, LIETRAN, developed to compute transient temperature fields in cylindrical reactor channels in accordance with the preceding analysis is contained in the Appendix. Since the relative power density in the fuel region, the relative coolant speed, and the inlet temperature have all been regarded as arbitrary functions of time, it is necessary for the user of LIETRAN to supply his own FUNCTION subprograms for the following quantities:

1. The relative power density in the fuel, $q\left(t_{k}\right)$, evaluated at the beginning of the kth time interval and called by POW(TIMEB) .

2. The vth order derivative, $q_{v}\left(t_{k}\right)$, of the relative power density evaluated at the beginning of the kth time interval and called by POWD(TIMEB, NU) .

3. The relative coolant speed, $u\left(t_{k}\right)$, evaluated at the beginning of the kth time interval and called by COOLS (TIMEB).

4. The vth order derivative, $u_{v}\left(t_{k}\right)$ of the relative coolant speed evaluated at the beginning of the kth time interval and called by COOLSD(TIMEB,NU).

5. The channel inlet temperature, $T\left(z_{l}, t_{k}\right)$, evaluated at the heginning of the kth time interval and called by TEMIN (TIMEB).

6. The vth order term in the Lie-series representation of the channel inlet temperature, de$\overline{\text { noted by }} T_{k}^{\nu}\left(z_{1}, t_{k}\right)$, evaluated at the beginning of the $k$ th time interval and called by TEMIND(TIMEB , NI) .

For example, let $T_{\text {in }}$ be the channel inlet temperature at the beginning of the transient and let $f(t)$ be the relative channel inlet temperature, so that

$$
T\left(z_{1}, t\right)=T_{\text {in }} f(t) .
$$

The Lie-series representation of the channel inlet temperature,

$$
T_{k}\left(z_{1}, t\right)=T_{k}^{0}\left(z_{1} ; t\right)+\sum_{v=1}^{\infty} \cdot T_{k}^{v}\left(z_{1}, t\right),
$$

holds for the kth timo intorval. In Eq. 116

$$
T_{k}^{0}\left(z_{1}, t\right)=T_{\text {in }} t\left(t_{k}\right),
$$

and

$$
\begin{gathered}
T_{k}^{\nu}\left(z_{1}, t\right)=\left.\frac{\left(t-t_{k}\right)^{\nu}}{v !} \frac{d^{\nu}}{d t^{\nu}} T\left(z_{1}, t\right)\right|_{t=t_{k}} \\
,(v=1,2,3, \ldots) .
\end{gathered}
$$

Combining Eqs. 115 and 118 yields

$$
T_{k}^{v}\left(z_{1}, t\right)=T_{\text {in }} f_{v}\left(t_{k}\right) \frac{\left(t-t_{k}\right)^{\nu}}{v !}
$$

in which $\mathbf{f}_{v}\left(t_{k}\right)$ is the vth order derivative of the relative chamnel inlet temperature evaluated at the beginning of the kth time interval. 
Appendix

Fortran Listing of LIETRAN

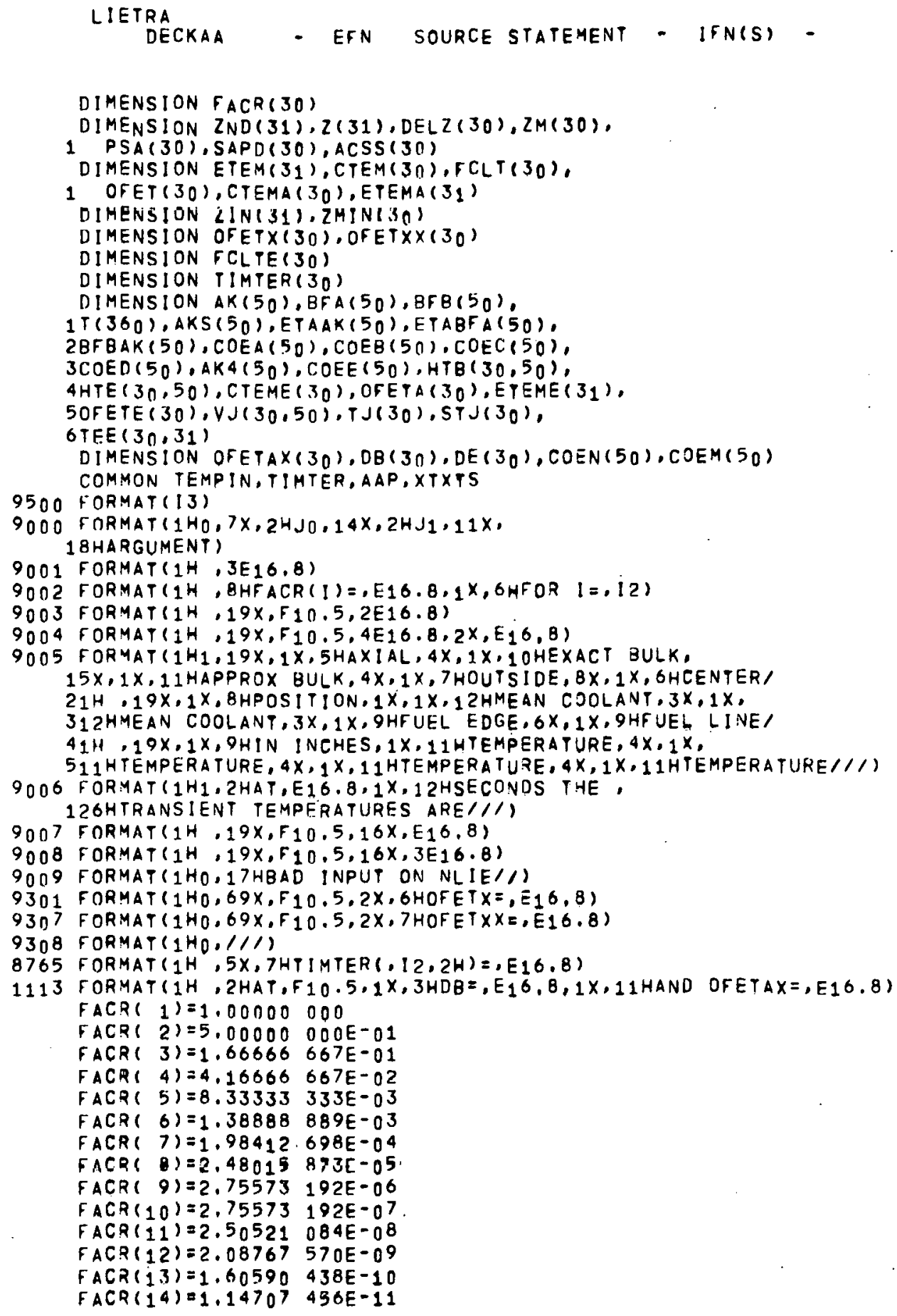




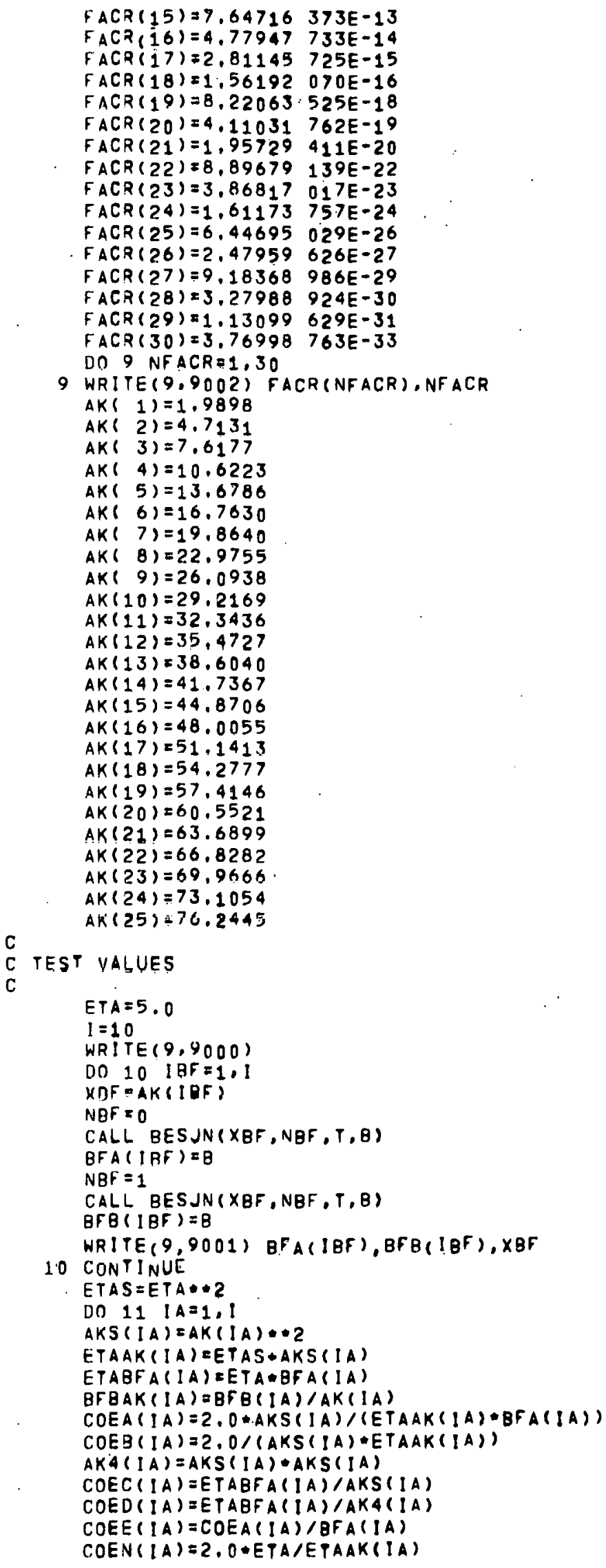




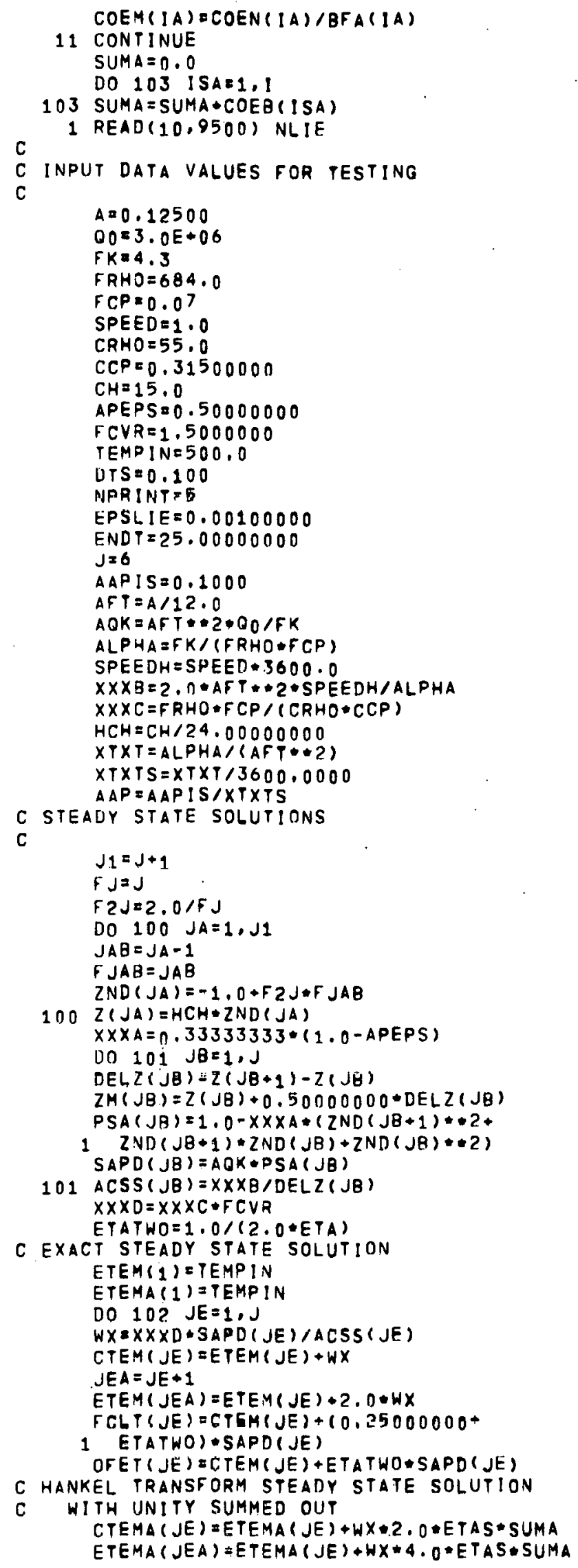




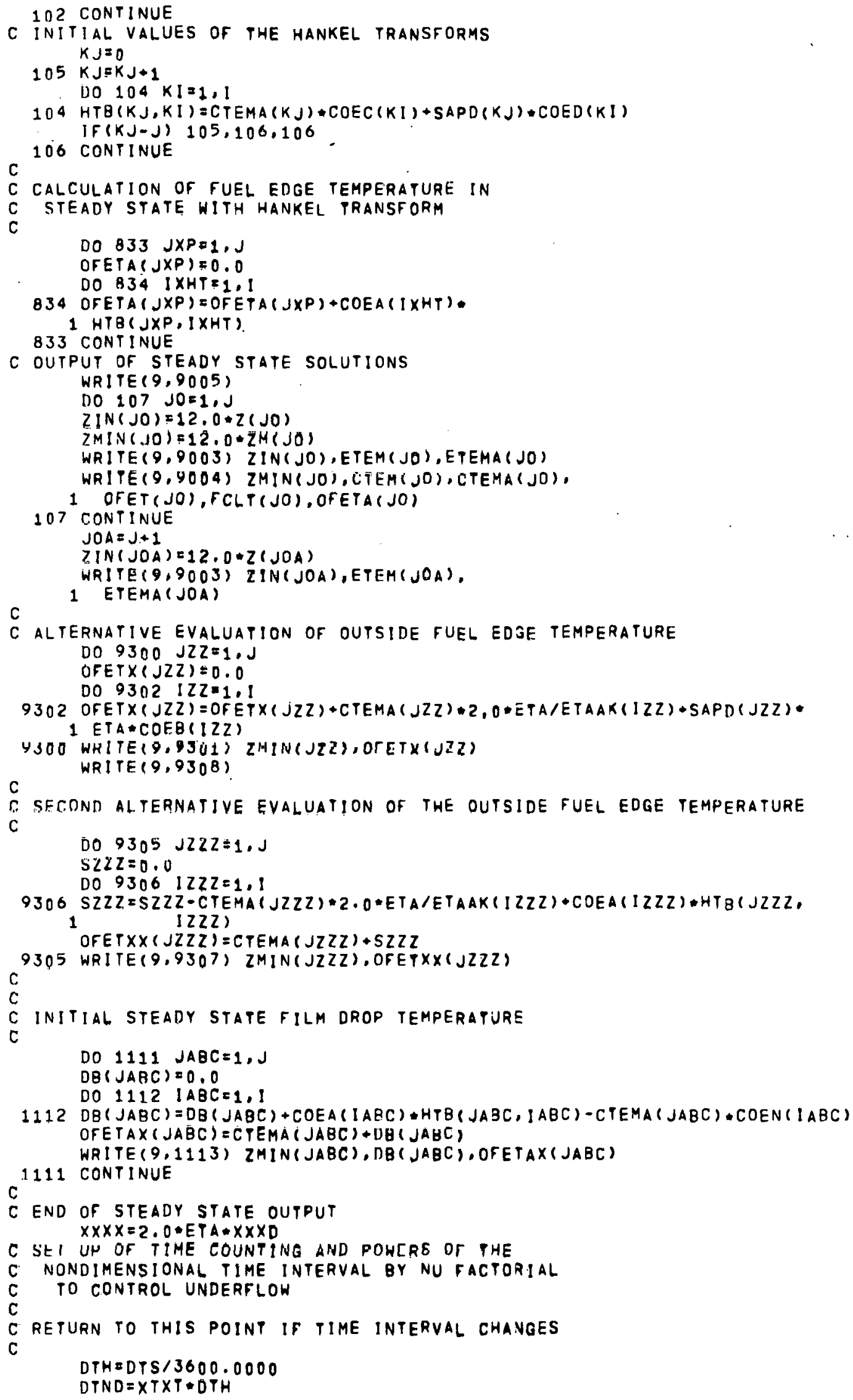




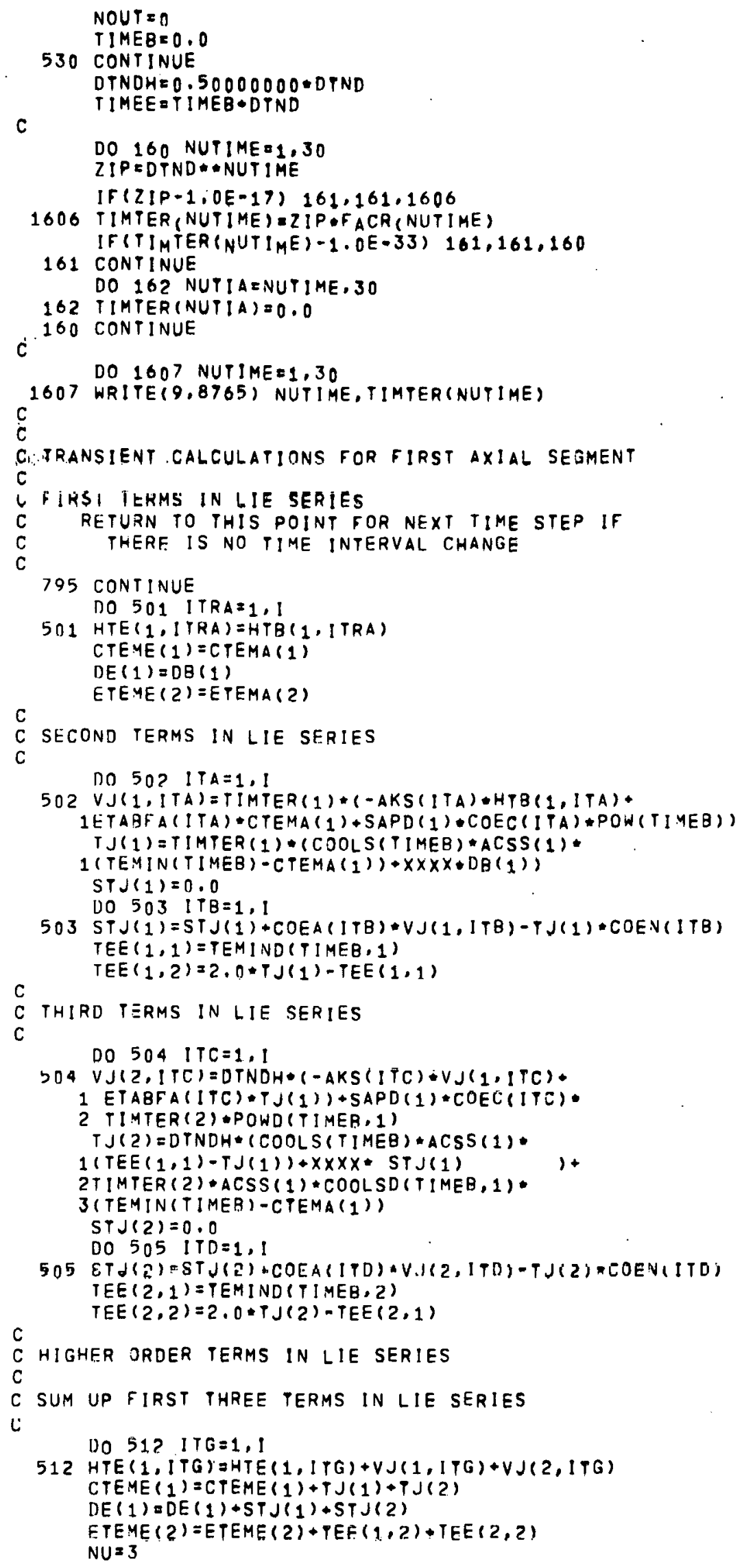




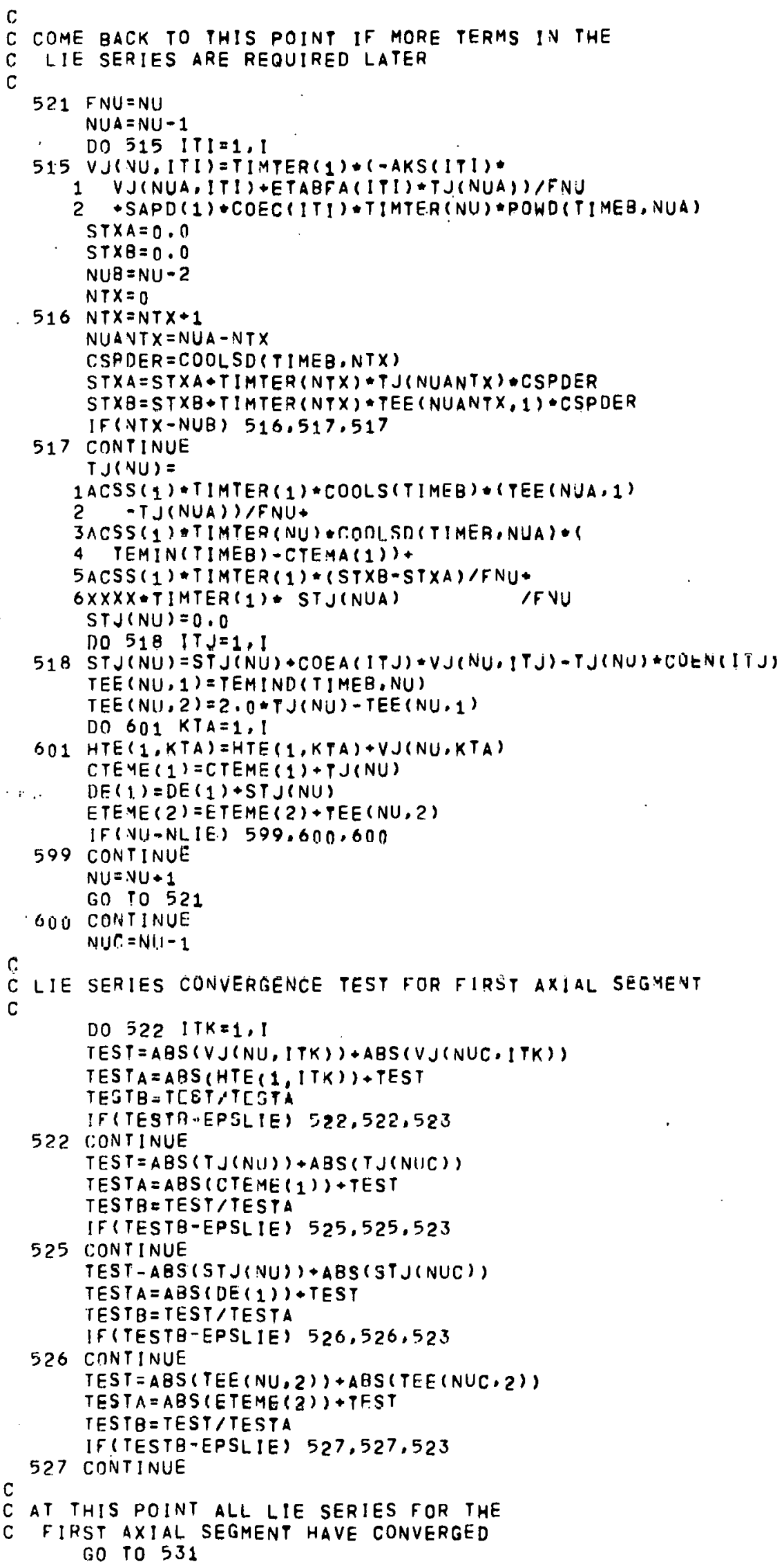




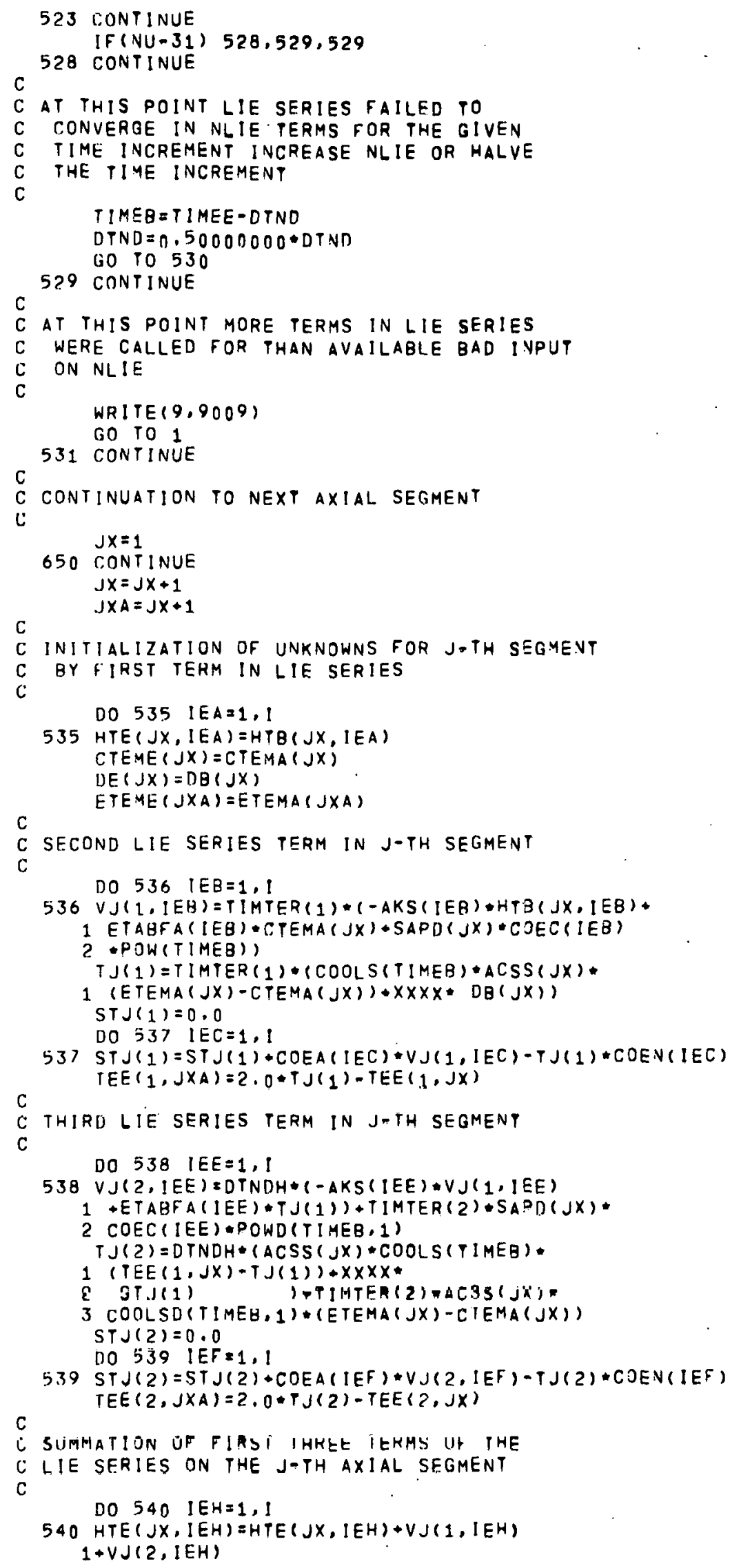




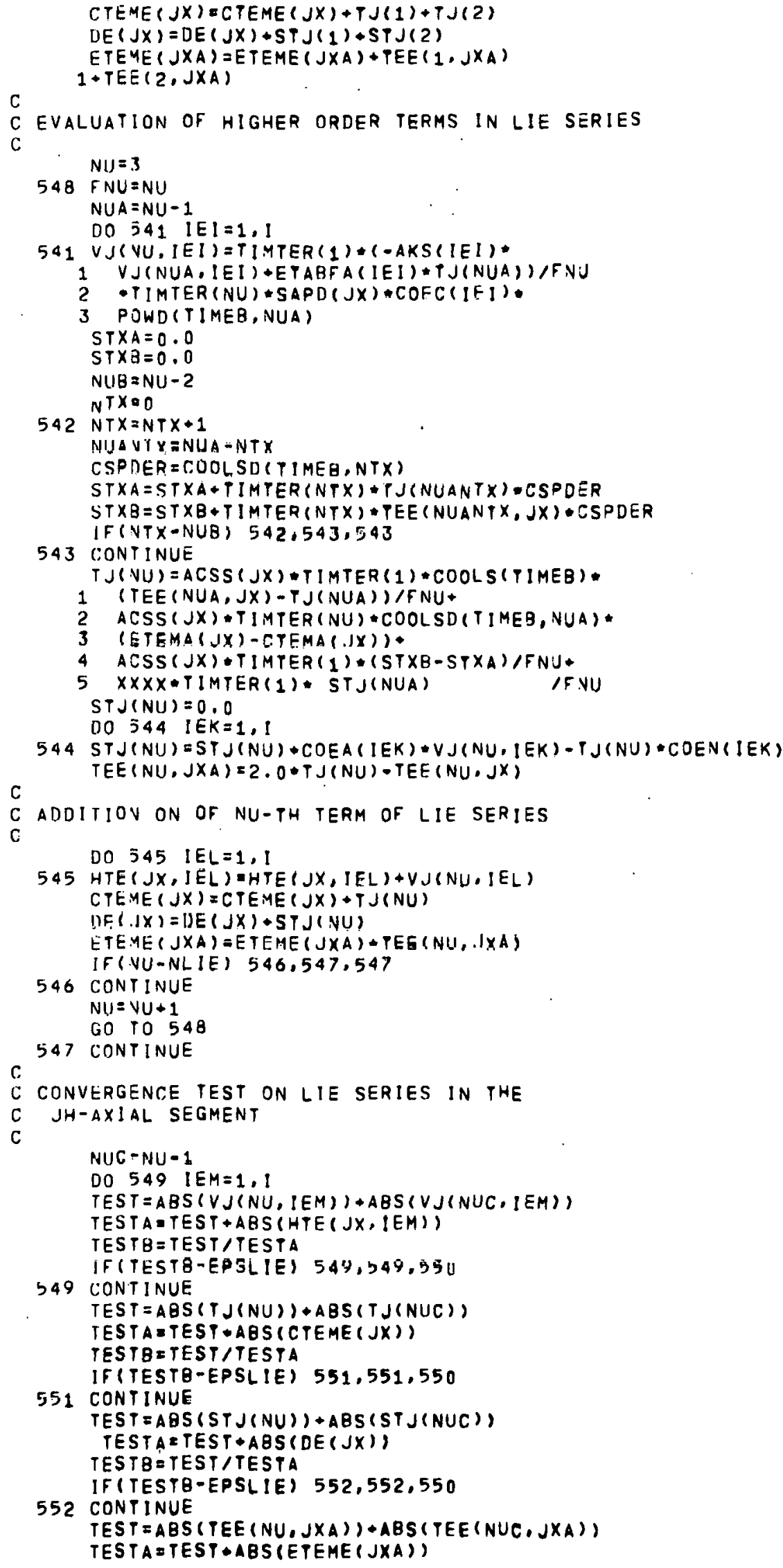




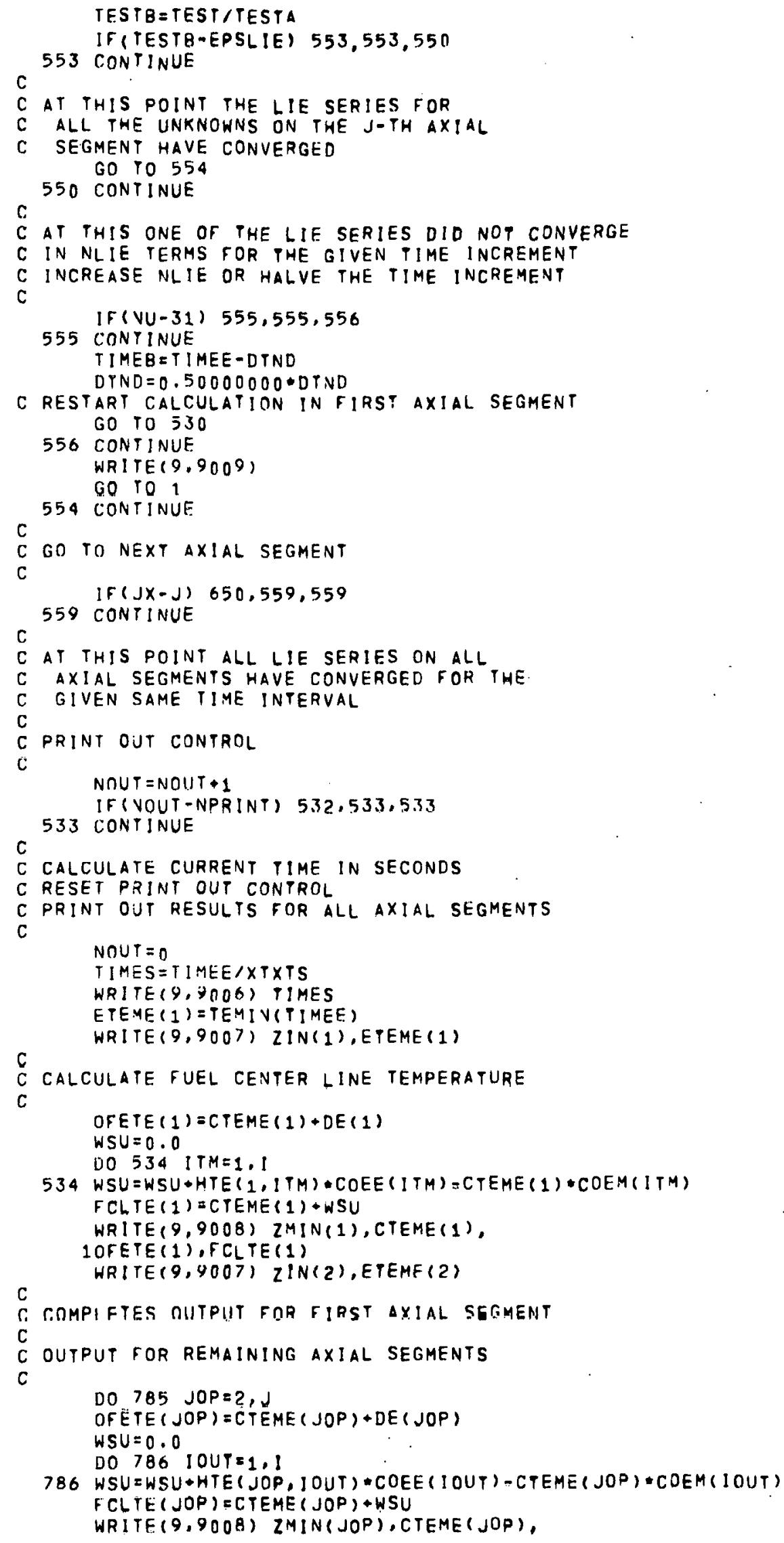




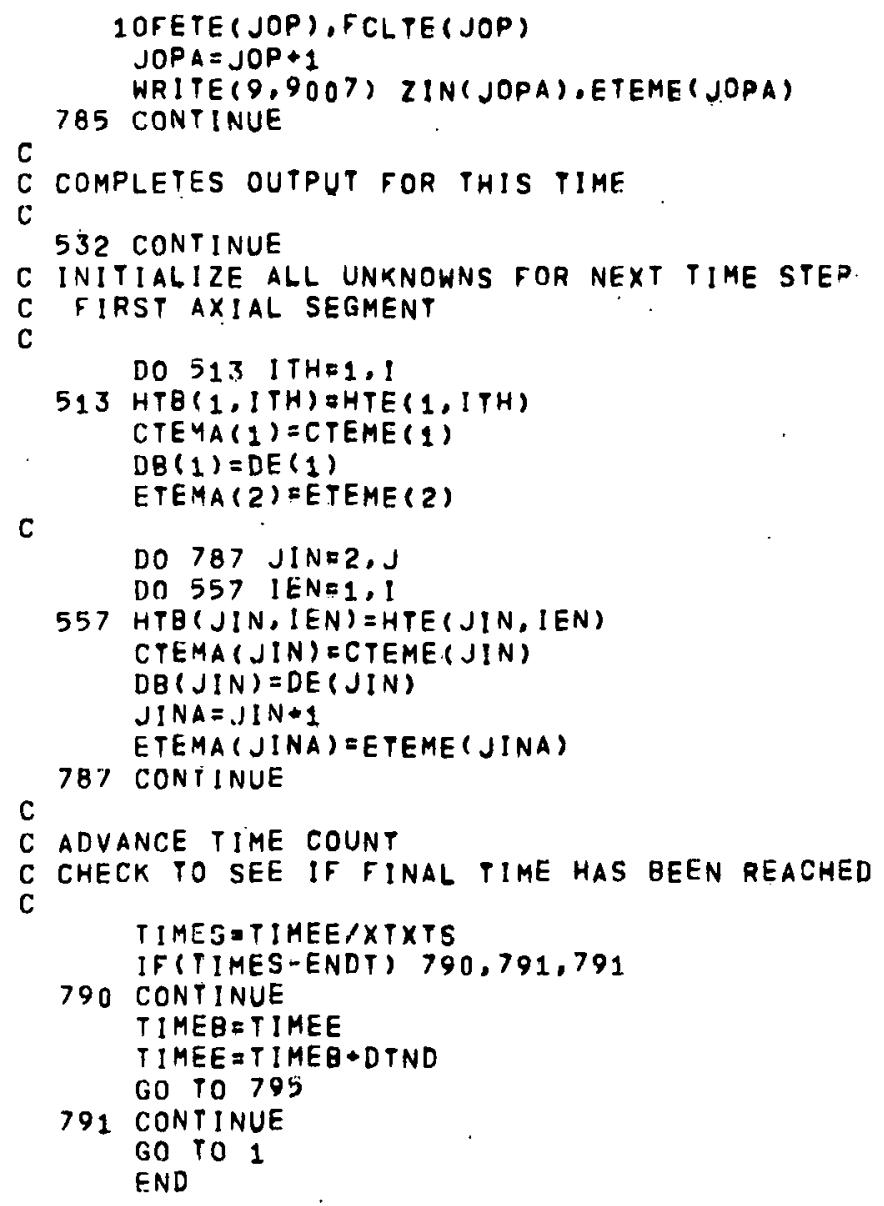


FROM : LASL, LOS ALAMOS, NEW MEXICO

SUBJECT: LA-3833

Enclosed are copies of a last Rerana Report for distribution in accordance with TID-4500, Standard Distritution List for Uiclassified Reports. Also enclosed are 47 copice for distribution to the United Kingdom and EURATOY. 